ments in their letter upon which I will briefly comment now.

At Rosses Point, Profs. Jones and Boswell have ascertained, by counting, that there still remain ten slabs of the cherty roof-blocks of large size. They compare this number with the twenty-six slabs of the re-deposited dolomitic floor-stone, and appear to attach importance to the latter's preponderance. Of course there is a preponderance. Furthermore, this preponderance will tend to become greater as time goes on and as more and more of the floor-stone becomes detached and re-deposited by the waves during storms. If Profs. Jones and Boswell were to study my photograph of the site, taken before any of the blocks had been disturbed, they could draw the following section :-

(a) Re-deposited dolomitic floor-stone.

(b) Collapsed roof-blocks of cherty limestone.

(c) Flakes, implements, and cores.

(d) Dolomitic floor-stone, in situ.

(e) Cherty limestone.

Such a section bears an interpretation alternative to that offered by them.

Profs. Jones and Boswell give their opinion that rapid coastal erosion is taking place in the Sligo area, and in support of this contention they instance, on Coney Island, a concrete emplacement now overhanging the cave at the north-west corner of the island, which, they state, once formed the base of a beacon since moved inland owing to encroachment by the sea. If they had sought their facts from the builders (as I have done) they would have ascertained :

1. The emplacement did not serve, and was not intended to serve, as the foundation for a beacon.

2. It was a platform made flat for the use of the men who pump sea-water for the containers of the beacons situated farther inland.

3. The cave was in existence immediately below the emplacement at the time of its building.

4. Poteen used to be made there !

All we can say with certainty is that the front of the cave has given way along a joint-plane subsequent to the building of the emplacement, and that there is no evidence of a recent date for the formation of the cave in question. There have been occasional falls of cliff along the Carboniferous Limestone coast-line of Gower, Wales. But Paviland Cave is palæolithic.

I may say that I have obtained additional archæological and geological evidence in support of my claim, but, with regard to the cultural age of the implements (as I took the opportunity to inform the Royal Irish Academy's delegation in April), it is not improbable that they will prove to be older than originally suggested. The impression I first gained was that the industry should be correlated with the massive Chellean culture stage as typified at Cromer, Norfolk. Though my opinion, in this respect, differs from that of my collaborator, Mr. Reid Moir, the fundamental importance of my claim-i.e. to have discovered traces of palæolithic man in Ireland and to have established an inter-glacial period for that country-remains unaffected.

June 6.

$$
\text { J. P. T. Burcherc. }
$$

\section{The Buoyancy of Whales.}

I AGREE with Sir Sidney Harmer (Nature, May 12, p. 748) that as the whale descends its chest is compressed and the density of its body is consequently increased. It is owing to this very fact (that is, its increased density) that the whale has difficulty in regaining the surface after descending to a great depth, and that there is consequently a limit to the depth to which it can safely descend.

Compression of the chest, however, does not account for all the phenomena. If nothing else took place, the dead whale would float when raised to the surface, and this is not the case, at any rate, not so far as I know. In explaining the facts it seems necessary to postulate the absorption or escape of the lung air. Death being due to asphyxia, as $I$ am about to show, the latter possibility (that is, the escape of the lung air) seems not unlikely.

The whales I spoke of were not allowed to sink to the bottom, but were suspended by the whale-line and were hauled up as soon as possible. In whaling language they 'died on the first harpoon' ; that is to say, were only harpooned once, and after 'sounding' or going vertically down to a great depth, died under water. They doubtless died from drowning or asphyxia, as the whalers say. There is no other way of accounting for their death. The pressure of the water has evidently no injurious effect on them, and the injury done them by the harpoon-at any rate by the hand one-is not serious enough to cause death.

Sometimes, however, the Greenland whale died under water " on the third or fourth harpoon," when it was already far spent and about to receive the coup de grâce with the lance. A case of this kind came under my notice in 1886. It is recorded in the Zoologist of 1887 , p. 97 . Briefly, the whale received a fourth gun harpoon, descended a few fathoms, died under water, and floated up dead. Strange to say, it came up tail first. Its death seemed to be due to syncope, and the pressure of the water at the trifling depth at which it died did not seem sufficient to squeeze the air out of it. Consequently it floated up.

Sir Sidney Harmer seems unwilling to believe that. whales use their lungs for hydrostatic purposes. I have shown that in recently dead whales the tendency of the body to float or sink depends on the state of the chest and lungs. It seems reasonable to suppose that the same is true during life. To arrive at the truth it is necessary to watch the whale when it is motionless, not when it is swimming about.

I have mentioned that the Greenland whale sometimes lies motionless at the surface with a part of its head above water and with its back awash. Scoresby tells us that when it is extended in this manner it "can sink downwards in the space of five or six seconds or less beyond the rezch of its human enemies," and Beale, speaking of the sperm whale, says, "occasionally when suddenly disturbed the whale has the power of sinking quickly and directly downwards in the horizontal position."

In conclusion, I think the air in the lungs of the whales in the intervals between the respirations must be in a state of compression, and that it is owing to this that each time the animal breathes an appearance is produced resembling a puff of steam escaping from a boiler.

Exmouth, May 31.

$$
\text { R. W. Gray. }
$$

\section{Physics and Metaphysics.}

THE writer of the review of "A Short History of Physics" (NATure, May 26) suggests an interesting speculation (p. 824) as to whether the great physical scientists "have not usurped the place of the metaphysicians," since "some modern theories make almost impossible demands upon the imagination of those without more than a fair amount of mathematical knowledge."

On the other hand, Mr. Selby's illuminating summary of "The Quantum Postulate and the

No. 3060, Vol. 121] 